The Astrophysical Journal, 300:415-419, 1986 January 1

(1) 1986. The American Astronomical Society. All rights reserved. Printed in U.S.A

\title{
CHEMISTRY OF CHLORINE IN DENSE INTERSTELLAR CLOUDS
}

\author{
Geoffrey A. Blake \\ Department of Chemistry, California Institute of Technology \\ AND \\ V. G. ANicich AND W. T. Huntress, Jr. \\ Jet Propulsion Laboratory, California Institute of Technology \\ Received 1985 March 18; accepted 1985 June 28
}

\begin{abstract}
Laboratory experiments and theoretical modeling show that the chemistry of chlorine is fairly simple in dense interstellar clouds, with $\mathrm{Cl}$ and $\mathrm{HCl}$ as the only species whose fractional abundances are significant. The estimated fraction of gas-phase chlorine present as $\mathrm{HCl}$ lies between $25 \%-65 \%$, in good agreement with the recent observations of the ground state $\mathrm{HCl}$ transition by Blake, Keene, and Phillips. These results, combined with the observational limits on $\mathrm{HCl}$, indicate that chlorine is not severely depleted in dense interstellar clouds.
\end{abstract}

Subject headings: interstellar: abundances — interstellar: molecules

\section{INTRODUCTION}

Elemental chlorine has been well studied in diffuse clouds by the Copernicus satellite, using optical and UV transitions of $\mathrm{Cl}$ I and $\mathrm{Cl}$ II, which have shown that chlorine is depleted by no more than a factor of 3 below the solar abundance $\left(\sim 3 \times 10^{-7}\right)$ in such clouds (Jura and York 1978). Searches for $\mathrm{HCl}$ and other molecular species have produced only upper limits to date (Smith et al. 1980), in contrast to some calculations (Jura 1974; Black and Dalgarno 1977) which suggested that detectable column densities of $\mathrm{HCl}$ should exist. More recent theoretical models now reproduce these observations quite well and indicate that molecular chlorine compounds do not play a significant role in diffuse clouds (van Dishoeck 1984). The chemistry of chlorine in dense interstellar clouds remains rather more uncertain, however. As one of the more volatile second-row elements, the gas-phase abundance of chlorine in these predominantly molecular clouds is expected to remain high. The ubiquitous nature of $\mathrm{H}_{2}$ in dense clouds led early model calculations to conclude that $\mathrm{HCl}$ would be the dominant, or sole, gas-phase chlorine reservoir in such objects and that rotational line emission from hydrogen chloride would contribute substantially to the energy balance of molecular clouds (Dalgarno et al. 1974). The large rotational constants of $\mathrm{HCl}$ place its pure rotational spectrum in the submillimeter and far-infrared wavelength regions in which high-resolution astronomical observations are both difficult and sparse.

Recently, however, Blake, Keene, and Phillips (1985) have successfully detected the $\mathrm{HCl}$ ground-state transition at 625.9 $\mathrm{GHz}$ toward the Orion molecular cloud. These observations indicate that while the amount of gas-phase hydrogen chloride is large, it is somewhat below that expected for an undepleted chlorine abundance fully associated into $\mathrm{HCl}$. In order to determine whether depletion mechanisms alore are responsible for this decrease, or whether chemical processes also limit the $\mathrm{HCl}$ abundance, we have carried out laboratory experiments and theoretical model calculations on the ionmolecule chemistry of interstellar chlorine. These studies have shown that $\mathrm{HCl}$ is a major, but not the sole, reservoir of gaseous chlorine in dense interstellar clouds, with neutral atomic chlorine remaining as the other significant species. We also find that, although higher than in diffuse clouds, the chlorine depletion is not severe in dense molecular clouds.

\section{CHEMICAL DATA}

Many of the reactions of importance to interstellar chlorine chemistry have not been previously measured in the laboratory. We have therefore measured a number of these reactions, particularly those involving $\mathrm{CCl}^{+}$, using the ion cyclotron resonance techniques discussed in Thorne, Anicich, and Huntress (1983). Table 1 summarizes the laboratory work

TABLE

LABORATORY RATE CONSTANTS FOR ION-MOLECULE REACTIONS INVOLVING CHLORINE

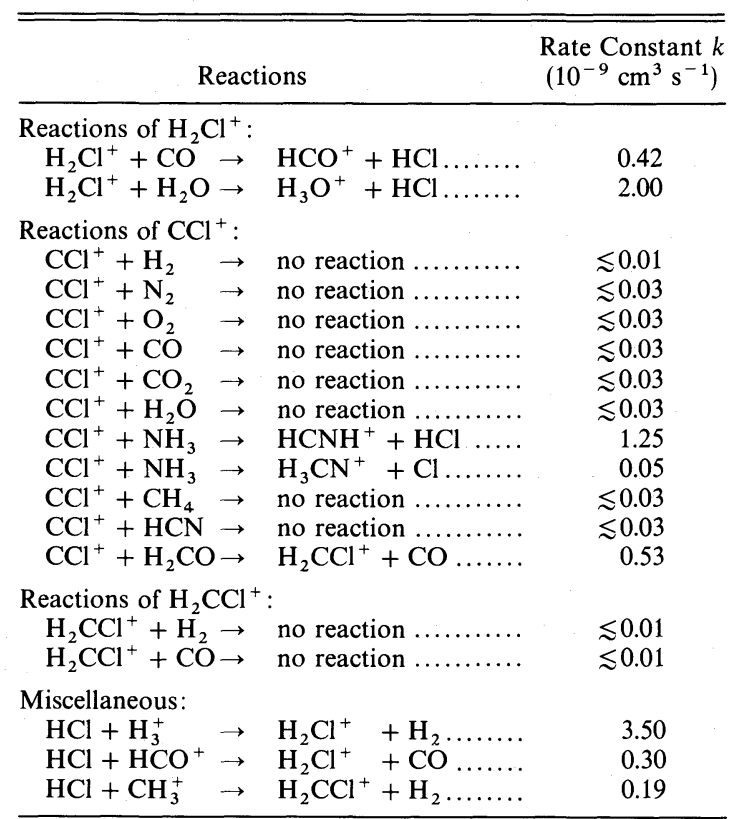


TABLE 2

Heats of Formation of Species Containing ChLORINE

\begin{tabular}{cccc}
\hline \hline Ions & $\begin{array}{c}\Delta H_{f}^{0} \\
(\mathrm{kCal})\end{array}$ & Neutrals & $\begin{array}{c}\Delta H_{f}^{0} \\
(\mathrm{kCal})\end{array}$ \\
\hline $\mathrm{Cl}^{+} \ldots \ldots \ldots$ & $327.7^{\mathrm{a}}$ & $\mathrm{Cl}$ & $29.1^{\mathrm{a}}$ \\
$\mathrm{HCl}^{+} \ldots \ldots \ldots$ & $271.8^{\mathrm{a}}$ & $\mathrm{HCl}$ & $-22.1^{\mathrm{a}}$ \\
$\mathrm{H}_{2} \mathrm{Cl}^{+} \ldots \ldots \ldots$ & $\sim 205^{\mathrm{b}}$ & $\ldots$ & $\ldots$ \\
$\mathrm{CCl}^{+} \ldots \ldots \ldots$ & $\lesssim 340 .^{\mathrm{c}}$ & $\mathrm{CCl}$ & $\sim 122 .{ }^{\mathrm{d}}$ \\
$\mathrm{H}_{2} \mathrm{CCl}^{+} \ldots \ldots$ & $\sim 227 .^{\mathrm{a}, \mathrm{e}}$ & $\ldots$ & $\ldots$ \\
\hline
\end{tabular}

a Rosenstock et al. 1977.

${ }^{\mathrm{b}}$ Calculated from proton affinities listed by Hartman et al. 1979.

${ }^{c}$ Calculated from the heat of formation $\mathrm{CCl}^{+}$and the upper limit determined for the ionization potential of $\mathrm{CCl}^{+}$

${ }^{\mathrm{d}}$ Calculated from average or estimated bond energies.

e Levin and Lias 1982

performed on the ion-molecule reactions of chlorine. The $\mathrm{CCl}^{+}$ and $\mathrm{H}_{2} \mathrm{CCl}^{+}$ions were generated by electron impact on chloroform and dichloromethane, while $\mathrm{H}_{2} \mathrm{Cl}^{+}$was produced via the reaction of $\mathrm{H}_{3}^{+}$and $\mathrm{HCl}$. The rapid proton transfer reactions from $\mathrm{H}_{2} \mathrm{Cl}^{+}$and the reactions leading to and involving $\mathrm{CCl}^{+}$and $\mathrm{H}_{2} \mathrm{CCl}^{+}$were neglected in the earliest dense cloud models (Dalgarno et al. 1974), but are quite important to the ion-molecule chemistry of chlorine. These reactions are the key result of the laboratory study.

The theoretical calculation used to model interstellar chlorine chemistry requires the rate coefficients of more reactions than can be currently measured, particularly those involving the reactive atomic species $\mathrm{C}$ and $\mathrm{O}$. Thermodynamic data and chemical intuition have therefore been used in place of laboratory measurements to predict the allowed reaction pathways and most probable products of processes involving these reactants. Listed in Table 2 are the heats of formation $\left(\Delta H_{f}^{0}\right)$ used to determine the reaction energetics for those pathways included in the model which have not been measured in the laboratory. Heats of formation for the $\mathrm{Cl}^{+}$and $\mathrm{HCl}^{+}$ions have been calculated from the ionization potentials (IP) and $\Delta H_{f}^{0}$ of the corresponding neutrals, while that of $\mathrm{H}_{2} \mathrm{Cl}^{+}$has been calculated using the measured proton affinity of $\mathrm{HCl}$.

No accepted values of $\Delta H_{f}^{0}$ exist for $\mathrm{CCl}^{+}$or $\mathrm{H}_{2} \mathrm{CCl}^{+}$. An upper limit of $\Delta \mathrm{H}_{f}^{0}\left(\mathrm{CCl}^{+}\right) \lesssim 340 \mathrm{kCal}$ per mole has been obtained by examining charge transfer reactions between $\mathrm{CCl}^{+}$and a number of low IP neutrals such as $\mathrm{NO}, \mathrm{CH}_{3} \mathrm{NH}_{2}$, and $\mathrm{Cl}_{2}$. No charge transfer was detected between any of these species, implying an upper limit of $9.26 \mathrm{eV}$ for IP(CCl), determined from NO. The low IPs of $\mathrm{CCl}$ and $\mathrm{H}_{2} \mathrm{CCl}$ are consistent with the observed stability and low reactivity of the $\mathrm{CCl}^{+}$and $\mathrm{H}_{2} \mathrm{CCl}^{+}$ions, which is explained in part by the fact that these ions are isoelectronic with the familiar and stable interstellar species $\mathrm{CS}$ and $\mathrm{H}_{2} \mathrm{CS}$.

\section{THE MODEL}

The procedure used to examine the interstellar chemistry of chlorine is essentially identical to that described by Thorne $e t$ al. (1984) in their study of interstellar phosphorus. The low fractional abundance of chlorine insures that, like phosphorus, its chemistry acts only as a small perturbation on the overall composition and chemistry of molecular clouds. Because of the low chlorine fractional abundance and the current limited understanding of chlorine ion-molecule chemistry, we have constructed a simple kinetic model in place of a large-scale theoretical calculation. This model employs the results of previous laboratory, astronomical, and theoretical modeling efforts to effectively decouple the interstellar chlorine chemistry from those processes occurring among the more abundant first-row elements. The Runge-Kutta procedure used to examine interstellar phosphorus has been implemented on a VAX/11-780 computer to solve the set of kinetic equations listed in Table 3. Exothermic reactions included in the model which have not been measured experimentally are assigned rate coefficients of $1 \times 10^{-9} \mathrm{~cm}^{3} \mathrm{~s}^{-1}$. These would represent upper limits and therefore introduce the maximum effect of the predicted channels.

The reactant abundances and density-dependent variables required by the kinetic procedure are listed in Table 4 . Only the chlorine-containing species listed in Table 2 have their abundances calculated by the model; the fractional abundances of important neutral atoms and molecules are assumed to be density independent and are fixed to the values determined from observational data, relying mainly on the broadband spectral-line searches of the Orion molecular cloud recently completed at the Owens Valley and Onsala Radio Observatories (Sutton et al. 1985; Johansson et al. 1984). Abundances for currently unobservable species are set to the values obtained by comprehensive chemical models of molecu-

TABLE 3

Chemical Equations Used in Model

\begin{tabular}{|c|c|c|c|c|}
\hline \multicolumn{4}{|c|}{ Reactions } & \multirow{2}{*}{$\begin{array}{l}\begin{array}{l}\text { Rate Constant } k \\
\left(10^{-9} \mathrm{~cm}^{3} \mathrm{~s}^{-1}\right)\end{array} \\
1.0 \times 10^{-8 \mathrm{a}}\end{array}$} \\
\hline $\mathrm{Cl}$ & + cosmic & $\mathrm{s} \rightarrow \mathrm{Cl}^{+}$ & $+e^{-}$. & \\
\hline $\mathrm{Cl}$ & $+\mathrm{H}^{+\mathrm{b}}$ & $\rightarrow \mathrm{Cl}^{+}$ & $+\mathrm{H} \ldots \ldots \ldots \ldots$ & $1.0^{\mathrm{a}}$ \\
\hline $\mathrm{Cl}$ & $+\mathrm{H}_{3}^{+b}$ & $\rightarrow \mathrm{HCl}^{+}$ & $+\mathrm{H}_{2} \ldots \ldots \ldots \ldots$ & $1.0^{\mathrm{a}}$ \\
\hline $\mathrm{HCl}$ & $+\mathrm{H}^{+}$ & $\rightarrow \mathrm{HCl}^{+}$ & $+\mathrm{H} \ldots \ldots \ldots \ldots$ & $4.0^{\mathrm{a}}$ \\
\hline $\mathrm{HCl}$ & $+\mathrm{He}^{+}$ & $\rightarrow \mathrm{Cl}^{+}$ & $+\mathrm{H}+\mathrm{He} \ldots$ & $3.3^{\mathrm{c}}$ \\
\hline $\mathrm{HCl}$ & $+\mathrm{H}_{3}^{+}$ & $\rightarrow \mathrm{H}_{2} \mathrm{Cl}^{+}$ & $+\mathrm{H}_{2} \ldots \ldots \ldots \ldots$ & $3.5^{\mathrm{d}}$ \\
\hline $\mathrm{HCl}$ & $+\mathrm{HCO}^{+}$ & $\rightarrow \mathrm{H}_{2} \mathrm{Cl}^{+}$ & $+\mathrm{CO} \ldots \ldots \ldots$ & $0.0004^{\mathrm{e}}$ \\
\hline $\mathrm{HCl}$ & $+\mathrm{C}^{+\mathrm{b}}$ & $\rightarrow \mathrm{CCl}^{+}$ & $+\mathrm{H} \ldots .$. & $1.0^{\mathrm{f}}$ \\
\hline $\mathrm{HCl}$ & $+\mathrm{CH}_{3}^{+}$ & $\rightarrow \mathrm{H}_{2} \mathrm{CCl}^{+}$ & $+\mathrm{H}_{2}$. & $0.13^{\mathrm{d}, \mathrm{e}}$ \\
\hline $\mathrm{Cl}^{+}$ & $+\mathrm{H}_{2}{ }^{\mathrm{b}}$ & $\rightarrow \mathrm{HCl}^{+}$ & $+\mathrm{H}^{2}$. & $1.0^{\mathrm{g}}$ \\
\hline $\mathrm{HCl}^{+}$ & $+e^{-2}$ & $\rightarrow \mathrm{Cl}$ & $+\mathrm{H} .$. & $300^{a}$ \\
\hline $\mathrm{HCl}^{+}$ & $+\mathrm{H}_{2}{ }^{\mathrm{b}}$ & $\rightarrow \mathrm{H}_{2} \mathrm{Cl}^{+}$ & $+\mathrm{H} \ldots \ldots$ & $1.30^{\mathrm{g}}$ \\
\hline $\mathrm{H}_{2} \mathrm{Cl}^{+}$ & $+e^{-}$ & $\rightarrow \mathrm{Cl}$ & $+\mathrm{H}_{2} \ldots \ldots \ldots \ldots$ & $1500^{\mathrm{a}}$ \\
\hline $\mathrm{H}_{2} \mathrm{Cl}^{+}$ & $+e^{-}$ & $\rightarrow \mathrm{HCl}$ & $+\mathrm{H} \ldots \ldots \ldots \ldots$ & $150 .^{\mathrm{b}}$ \\
\hline $\mathrm{H}_{2} \mathrm{Cl}^{+}$ & $+C^{b}$ & $\rightarrow \mathrm{CCl}^{+}$ & $+\mathrm{H}_{2} \ldots \ldots \ldots$ & $0.5^{\mathrm{a}}$ \\
\hline $\mathrm{H}_{2}^{2} \mathrm{Cl}^{+}$ & $+C^{b}$ & $\rightarrow \mathrm{HCl}$ & $+\mathrm{CH}^{+} \ldots \ldots \ldots$ & $0.5^{\mathrm{a}}$ \\
\hline $\mathrm{H}_{2} \mathrm{Cl}^{+}$ & $+\mathrm{S}$ & $\rightarrow \mathrm{HCl}$ & $+\mathrm{HS}^{+} \ldots \ldots$. & $1.0^{\mathrm{a}}$ \\
\hline $\mathrm{H}_{2} \mathrm{Cl}^{+}$ & $+\mathrm{CO}^{\mathrm{b}}$ & $\rightarrow \mathrm{HCl}$ & $+\mathrm{HCO}^{+} \ldots \ldots$ & $0.73^{\mathrm{d}, \mathrm{e}}$ \\
\hline $\mathrm{H}_{2} \mathrm{Cl}^{+}$ & $+\mathrm{H}_{2} \mathrm{O}$ & $\rightarrow \mathrm{HCl}$ & $+\mathrm{H}_{3} \mathrm{O}^{+} \ldots \ldots$. & $0.73^{\mathrm{d}}$ \\
\hline $\mathrm{CCl}^{+}$ & $+e^{-}$ & $\rightarrow \mathrm{Cl}$ & $+\mathrm{C} \quad \ldots \ldots \ldots$ & $300 .^{a}$ \\
\hline $\mathrm{CCl}^{+}$ & $+\mathrm{C}$ & $\rightarrow \mathrm{Cl}$ & $+\mathrm{C}_{2}^{+} \ldots \ldots \ldots \ldots$ & $1.0^{\mathrm{a}}$ \\
\hline $\mathrm{CCl}^{+}$ & $+\mathrm{N}$ & $\rightarrow \mathrm{Cl}$ & $+\mathrm{CN}^{+} \ldots \ldots \ldots$ & $1.0^{\mathrm{a}}$ \\
\hline $\mathrm{CCl}^{+}$ & $+\mathrm{O}^{\mathrm{b}}$ & $\rightarrow \mathrm{Cl}$ & $+\mathrm{CO}^{+} \ldots \ldots \ldots$ & $1.0^{\mathrm{a}}$ \\
\hline $\mathrm{CCl}^{+}$ & $+\mathrm{NH}_{3}$ & $\rightarrow \mathrm{HCl}$ & $+\mathrm{HCNH}^{+} \ldots$ & $1.30^{\mathrm{d}}$ \\
\hline $\mathrm{CCl}^{+}$ & $+\mathrm{H}_{2} \mathrm{CO}$ & $\rightarrow \mathrm{H}_{2} \mathrm{CCl}^{+}$ & $+\mathrm{CO} \ldots \ldots \ldots$ & $0.53^{d}$ \\
\hline $\mathrm{H}_{2} \mathrm{CCl}^{+}$ & $+e^{-}$ & $\rightarrow \mathrm{Cl}$ & $+\mathrm{CH}_{2} \ldots \ldots \ldots$ & $300 .^{a}$ \\
\hline $\mathrm{H}_{2} \mathrm{CCl}^{+}$ & $+\mathrm{C}$ & $\rightarrow \mathrm{HCl}$ & $+\mathrm{C}_{2} \mathrm{H}^{+} \ldots \ldots$ & $1.0^{\mathrm{a}}$ \\
\hline $\mathrm{H}_{2} \mathrm{CCl}^{+}$ & $+\mathrm{O}^{\mathrm{b}}$ & $\rightarrow \mathrm{HCl}$ & $+\mathrm{HCO}^{+} \ldots$. & $1.0^{\mathrm{a}}$ \\
\hline $\mathrm{H}_{2} \mathrm{CCl}^{+}$ & $+\mathrm{H}_{2} \mathrm{O}$ & $\rightarrow \mathrm{HCl}$ & $+\mathrm{H}_{3} \mathrm{CO}^{+} \ldots$ & $1.90^{\mathrm{a}}$ \\
\hline
\end{tabular}

a Guessed reaction and estimated rate constant.

b Most significant reactions.

c Bush et al. 1973.

d Measured in this work.

c Smith and Adams 1985.

f Anicich et al. 1976.

g Smith and Adams 1981. 
TABLE 4

Constants AND Density-DEPENDENT Variables IN THE CHLORINE MODEL

\begin{tabular}{lcc}
\hline \hline & Constants & Density-dependent Variables \\
\hline$\gamma$ & $=1 \times 10^{-17} \mathrm{~s}^{-1} \ldots \ldots$ & $f_{\mathrm{H}^{+}} \approx 5 \times 10^{-10} / n\left(f_{\mathrm{O}}+f_{\mathrm{H}_{2} \mathrm{O}}\right)$ \\
$f_{\mathrm{Cl}}=1 \times 10^{-7} \ldots \ldots \ldots \ldots$ & $f_{\mathrm{He}^{+}} \approx 2.5 \times 10^{-10} / n f_{\mathrm{CO}}$ \\
$f_{\mathrm{O}}=5 \times 10^{-5} \ldots \ldots \ldots \ldots \ldots$ & $f_{\mathrm{O}^{+}} \approx 2 \times 10^{-11} / n f_{\mathrm{H}_{2} \mathrm{O}}$ \\
$f_{\mathrm{C}}=5 \times 10^{-6} \ldots \ldots \ldots \ldots \ldots$ & $f_{\mathrm{CH}_{3}+} \approx 5 \times 10^{-11} / n f_{\mathrm{O}}$ \\
$f_{\mathrm{N}}=2 \times 10^{-6} \ldots \ldots \ldots \ldots$ & $f_{\mathrm{H}_{3}+}+f_{\mathrm{HCO}^{+}} \approx 3 \times 10^{-12} / n f_{e}$ \\
$f_{\mathrm{CO}}=5 \times 10^{-5} \ldots \ldots \ldots \ldots \ldots$ & $\ldots$ \\
$f_{\mathrm{H}_{2} \mathrm{O}}=2 \times 10^{-6} \ldots \ldots \ldots \ldots$ & $\cdots$ \\
$f_{\mathrm{NH}_{3}}=1 \times 10^{-7} \ldots \ldots \ldots \ldots$ & $\cdots$ \\
$f_{\mathrm{H}_{2} \mathrm{CO}}=1 \times 10^{-8} \ldots \ldots \ldots \ldots \ldots$ & $\cdots$ \\
$f_{e}=1 \times 10^{-8} \ldots \ldots \ldots \ldots$ & $\cdots$ \\
\hline
\end{tabular}

lar clouds (Prasad and Huntress 1980; Graedel, Langer, and Frerking 1982; Leung, Herbst, and Huebner 1984), while those for the density-dependent variables (ions) listed in Table 4 are calculated from equations incorporating the major production and destruction channels found from such theoretical models of oxygen-rich dense clouds $\left(10^{3}<n<10^{6} \mathrm{~cm}^{-3}\right)$.

The model results for a cloud of "typical" composition with a density of $10^{5}$ molecules $\mathrm{cm}^{-3}$ are listed in Table 5 and are quite similar to that found for phosphorus (Thorne et al. 1984). A significant amount of atomic material remains, and two neutral species, $\mathrm{Cl}$ and $\mathrm{HCl}$, dominate the interstellar chlorine chemistry, comprising $\sim 99.9 \%$ of the gas-phase chlorine abundance. $\mathrm{H}_{2} \mathrm{Cl}^{+}$and $\mathrm{CCl}^{+}$follow the neutral species in abundance, but are lower by at least a factor of 1000 . The dominant production and loss channels for each species are indicated by note (b) in Table 3 and are illustrated in Figure 1, which summarizes the important chlorine chemistry in dense clouds, as judged by this reduced set of reactions. Again, none of the interstellar nonchlorine species are significantly affected by this chemistry because of the low fractional abundance of chlorine.

The prediction that $\mathrm{HCl}$ is a major component of the gasphase chlorine abundance in dense clouds is in agreement with astronomical observations and shows that the species comprising interstellar chlorine differ significantly in diffuse and dense clouds. Several modifications to early chlorine models, which
TABLE 5

Chlorine Model Results

\begin{tabular}{cc}
\hline \hline Species & $\begin{array}{c}\text { Fractional Abundance } \\
\text { (for } f_{\Sigma \mathrm{Cl}}=10^{-7} \text { ) }\end{array}$ \\
\hline $\mathrm{Cl} \ldots \ldots \ldots \ldots \ldots \ldots \ldots$ & $3.8 \times 10^{-8}$ \\
$\mathrm{HCl} \ldots \ldots \ldots \ldots \ldots \ldots$ & $6.2 \times 10^{-8}$ \\
$\mathrm{Cl}^{+} \ldots \ldots \ldots \ldots \ldots \ldots$ & $1.2 \times 10^{-17}$ \\
$\mathrm{HCl}^{+} \ldots \ldots \ldots \ldots \ldots \ldots$ & $3.9 \times 10^{-17}$ \\
$\mathrm{H}_{2} \mathrm{Cl}^{+} \ldots \ldots \ldots \ldots \ldots \ldots$ & $3.3 \times 10^{-12}$ \\
$\mathrm{CCl}^{+} \ldots \ldots \ldots \ldots \ldots \ldots$ & $2.4 \times 10^{-13}$ \\
$\mathrm{H}_{2} \mathrm{CCl}^{+} \ldots \ldots \ldots \ldots \ldots$ & $1.3 \times 10^{-15}$ \\
\hline
\end{tabular}

produced too much $\mathrm{HCl}$ and too little $\mathrm{Cl}^{+}$, have been suggested to explain the lack of $\mathrm{HCl}$ in diffuse clouds. In these objects, neutral atomic chlorine is ionized by the ambient UV field and the resulting $\mathrm{Cl}^{+}$then produces the ionic precursor to hydrogen chloride, $\mathrm{H}_{2} \mathrm{Cl}^{+}$, via $\mathrm{H}$-atom abstraction reactions with $\mathrm{H}_{2}$ :

$$
\begin{aligned}
\mathrm{Cl}^{+}+\mathrm{H}_{2} & \rightarrow \mathrm{HCl}^{+}+\mathrm{H}, \\
\mathrm{HCl}^{+}+\mathrm{H}_{2} & \rightarrow \mathrm{H}_{2} \mathrm{Cl}^{+}+\mathrm{H} .
\end{aligned}
$$

The high electron abundance in diffuse clouds rapidly neutralizes $\mathrm{H}_{2} \mathrm{Cl}^{+}$, which does not react with $\mathrm{H}_{2}$, producing $\mathrm{Cl}$ and $\mathrm{HCl}$ :

$$
\mathrm{H}_{2} \mathrm{Cl}^{+}+e^{-}-\begin{aligned}
& \mathrm{Cl}+\mathrm{H}_{2} \\
& \mathrm{HCl}+\mathrm{H} .
\end{aligned}
$$

The major loss channels for $\mathrm{HCl}$ are photodissociation and reaction with $\mathrm{C}^{+}$. By including the $\mathrm{C}^{+}$channel, neglected in earlier models, increasing the $\mathrm{HCl}$ photodissociation rates, as has been suggested by recent ab initio calculations (van Dishoeck, van Hemert, and Dalgarno 1982), and using a small $(\lesssim 10 \%)$ branching ratio into channel $(3 \mathrm{~b})$, van Dishoeck (1984) has been able to drive the predicted $\mathrm{HCl}$ abundance to below the derived observational upper limits while simultaneously increasing the $\mathrm{Cl}^{+}$abundance to near that observed if a slow temperature-dependent rate constant is used for reaction (1). Experimental measurements by Smith and Adams

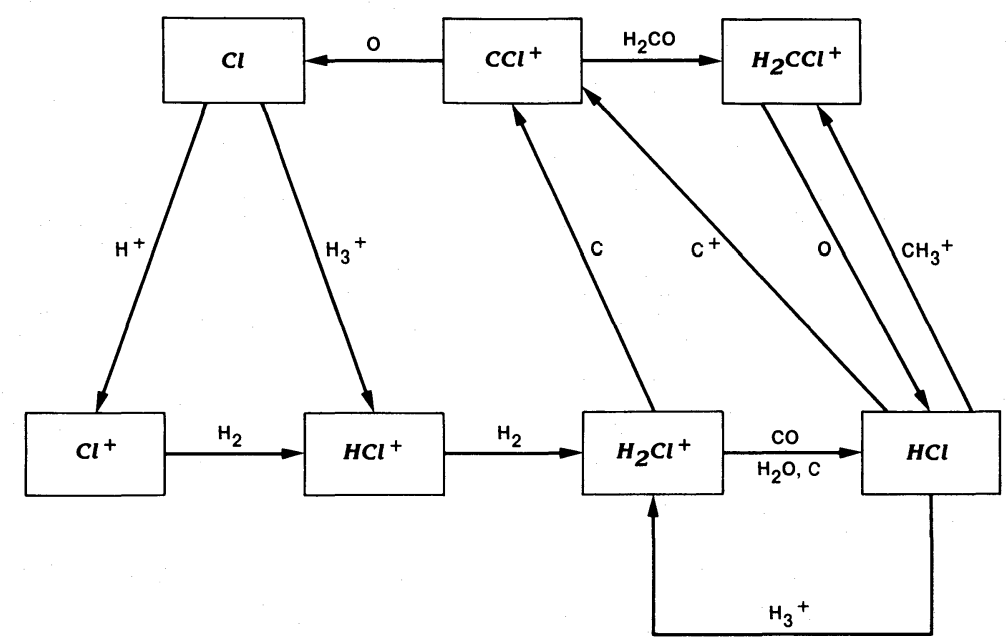

FIG. 1.-Summary of reactions that were found to be important in the dense cloud model. Arrows indicate reaction pathways: the species written next to the arrows indicate the other reactant in the bimolecular reaction. 
(1981) to temperatures as low as $80 \mathrm{~K}$ indicate that both reactions (1) and (2) are reasonably temperature insensitive, but that reaction (1) is only mildly exothermic $(\Delta H \approx 5 \mathrm{kCal}$ per mole). A modest activation barrier cannot, therefore, be excluded at very low temperatures.

In dense clouds any atomic chlorine will remain predominantly neutral, so the formation of hydrogen chloride is initiated mainly by the reaction of $\mathrm{Cl}$ and $\mathrm{H}_{3}^{+}$:

$$
\mathrm{Cl}+\mathrm{H}_{3}^{+} \rightarrow \mathrm{HCl}^{+}+\mathrm{H}_{2},
$$

followed by reactions (2) and (3). A slow reaction between $\mathrm{Cl}^{+}$ and $\mathrm{H}_{2}$ would therefore not limit the production of $\mathrm{HCl}$ in dense clouds. The proton affinity of $\mathrm{HCl}$, which is slightly below that of $\mathrm{CO}$, implies that $\mathrm{H}_{2} \mathrm{Cl}^{+}$will react rapidly with abundant interstellar neutral species, such as $\mathrm{CO}$ and $\mathrm{H}_{2} \mathrm{O}$, to produce $\mathrm{HCl}$ :

$$
\begin{aligned}
\mathrm{H}_{2} \mathrm{Cl}^{+}+\mathrm{CO} & \rightarrow \mathrm{HCl}+\mathrm{HCO}^{+}, \\
\mathrm{H}_{2} \mathrm{Cl}^{+}+\mathrm{H}_{2} \mathrm{O} & \rightarrow \mathrm{HCl}+\mathrm{H}_{3} \mathrm{O}^{+} .
\end{aligned}
$$

Even though the difference between the proton affinities of $\mathrm{HCl}$ and $\mathrm{CO}$ is very small ( $\$ 3 \mathrm{kCal}$ per mole), reaction (5) proceeds rapidly at $300 \mathrm{~K}$ (Table 1). Smith and Adams (1985) have also shown reaction (5) to proceed rapidly at lower temperatures, but that the reverse reaction is very slow. For the low predicted electron abundance $\left[f\left(e^{-}\right) \approx 10^{-8}\right]$ and high molecular content $\left[f(\mathrm{CO}) \approx 10^{-4}\right]$ of dense interstellar clouds, reactions (5) and (6) proceed at significantly faster rates than the electron recombination processes listed in reactions (3a) and (3b), and the impact of any reduction of the branching ratio into channel (3b) is small. Thus, the removal of $\mathrm{H}_{2} \mathrm{Cl}^{+}$by electrons in dense, dark clouds is orders of magnitude less efficient than in diffuse clouds, and the production rates of chlorine-bearing molecules are correspondingly higher. One might therefore naively expect that chlorine would be fully associated into $\mathrm{HCl}$ in dense clouds, since the major impediments to its production in diffuse clouds are no longer of importance. For the most part this is true, but several processes also act to limit the $\mathrm{HCl}$ fraction to $\sim 50 \%$ of the available chlorine abundance.

The largest $\mathrm{HCl}$ loss channels involve reactions of $\mathrm{H}_{2} \mathrm{Cl}^{+}$ with $\mathrm{C}$, and $\mathrm{HCl}$ with $\mathrm{C}^{+}$, both of which produce $\mathrm{CCl}^{+} . \mathrm{CCl}^{+}$ is isoelectronic with $\mathrm{CS}$ and is quite stable. The IP of $\mathrm{CCl}$ is low, and the $\mathrm{CCl}^{+}$ion is therefore relatively unreactive (see Table 1). Reaction with $O$, charge transfer to neutrals, and electron recombination are the most likely loss processes for $\mathrm{CCl}^{+}$in dense clouds. The net effect of these reactions, as shown in Figure 1, is to regenerate $\mathrm{Cl}$ and to establish a reaction pathway which cycles the chlorine rapidly between $\mathrm{Cl}$ and $\mathrm{HCl}$. All other species in this pathway have abundances which are quite small with respect to the neutral endpoints. The steady state abundance ratio of $\mathrm{Cl}$ to $\mathrm{HCl}$ is fairly insensitive to order of magnitude variations in the chemical composition of the model molecular clouds, being most sensitive to the abundance of $\mathrm{C}^{+}$and the rate constant for the reaction of $\mathrm{H}_{2} \mathrm{Cl}^{+}$ with $\mathrm{CO}$. The backward channel in reaction (5) is not important because proton transfer between $\mathrm{HCl}$ and $\mathrm{H}_{3}^{+}$occurs at a much faster rate, but the reaction of $\mathrm{H}_{2} \mathrm{Cl}^{+}$and $\mathrm{CO}$ contributes substantially to the predicted $\mathrm{HCl}$ abundance. Even so, alteration of the $\mathrm{C}^{+}$abundance by factors of 10 and complete elimination of the proton transfer reaction between $\mathrm{H}_{2} \mathrm{Cl}^{+}$and $\mathrm{CO}$ only change the estimated fractional abundance of $\mathrm{HCl}$ by at most a factor of 2 , with the higher and lower $\mathrm{C}^{+}$abundances producing less or more $\mathrm{HCl}$. Order of magnitude variations in other important reactants such as $\mathrm{C}, \mathrm{O}$, and $e^{-}$produce even smaller changes in the predicted $\mathrm{HCl}$ abundance, on the order of $15 \%$ or less.

Astronomical observations and the predictions of large-scale modeling efforts suggest that the $\mathrm{C}$ and $\mathrm{C}^{+}$atoms will have significant abundances only for moderate density regions and that $\mathrm{CO}$ will dominate the carbon abundance in very dense cloud cores (Keene et al. 1985; Prasad and Huntress 1980; Leung, Herbst, and Huebner 1984; Tarafdar et al. 1985), implying that the abundance of $\mathrm{HCl}$ should increase with density. By incorporating these predictions into our model we find that the $\mathrm{HCl}$ abundance does increase with density, but that for densities above $10^{5}$ this increase is not rapid. We therefore expect the fractional abundance of $\mathrm{HCl}$ in the central regions of giant molecular clouds to rise smoothly with density, with a fairly sharp increase in abundance where the column density in the outer cloud halo becomes sufficiently high such that photodissociation processes may be ignored, as is shown in Figure 2. For regions outside this photodissociation transition zone the remaining chlorine will be a mixture of $\mathrm{Cl}_{\text {and }} \mathrm{Cl}^{+}$, while inside this zone the atomic chlorine will remain predominantly neutral. Under all of these conditions, the predicted fraction of gas-phase chlorine present as $\mathrm{HCl}$ varies between $25 \%-65 \%$ in dense clouds. This produces an estimated fractional abundance of $X(\mathrm{HCl}) \approx 2.5-$ $6.5 \times 10^{-8}$ for a depletion factor of 3 , in good agreement with the observational estimates of $0.5-5.0 \times 10^{-8}$ (Blake, Keene, and Phillips 1985).

\section{CONCLUSIONS}

Simple kinetic modeling of interstellar chlorine chemistry shows that reactions of $\mathrm{H}_{3}^{+}+\mathrm{Cl}$ and $\mathrm{H}_{2}+\mathrm{HCl}^{+}$, in combination with rapid proton transfer reactions involving $\mathrm{H}_{2} \mathrm{Cl}^{+}$, produce substantial amounts of $\mathrm{HCl}$ in dense interstellar clouds in agreement with astronomical observations. The kinetic model also predicts that reactions of $\mathrm{H}_{2} \mathrm{Cl}^{+}+\mathrm{C}$ and $\mathrm{HCl}+\mathrm{C}^{+}$will regenerate atomic chlorine, leading to a chemical cycle in which $\mathrm{Cl}$ and $\mathrm{HCl}$ both retain significant gas-phase abundances. The predictions that $\mathrm{Cl}$ is also a major repository of chlorine in dense clouds and that $\mathrm{Cl}$ and $\mathrm{HCl}$ by themselves consitute the overwhelming fraction of chlorine in such objects may be tested by observing the fine-structure transition of atomic chlorine at $11.3 \mu \mathrm{m}$ in absorption toward such objects as Orion. The frequency of this transition is known to better than $0.3 \mathrm{~km} \mathrm{~s}^{-1}$ from infrared laser magnetic resonance (LMR) work (Dagenais, Johns, and McKellar 1976), and calculations indicate that for the suggested $\mathrm{Cl}$ abundance, the optical depth of the fine-structure transition should approach or exceed unity, making its detection feasible with high-resolution instruments.

Finally, the chlorine depletion in dense interstellar clouds may be estimated by combining the calculated model $\mathrm{HCl}$ fractional abundances with limits inferred from astronomical observations of the $J=1 \rightarrow 0$ transition. For a cosmic chlorine abundance of $3 \times 10^{-7}$, our results indicate that the chlorine depletion in Orion lies between 3-30. The large uncertainty arises mainly from difficulties associated with the astronomical observations and their interpretation. As mentioned earlier, Jura and York (1978) find from optical studies that chlorine in diffuse clouds is depleted by no more than a factor of 3 , although more recent work by Tarafdar, Prasad, and Huntress (1983) and Harris, Gry, and Bromage (1984) argues that elemental depletion in clouds increases strongly with either $\mathbf{H}_{2}$ 


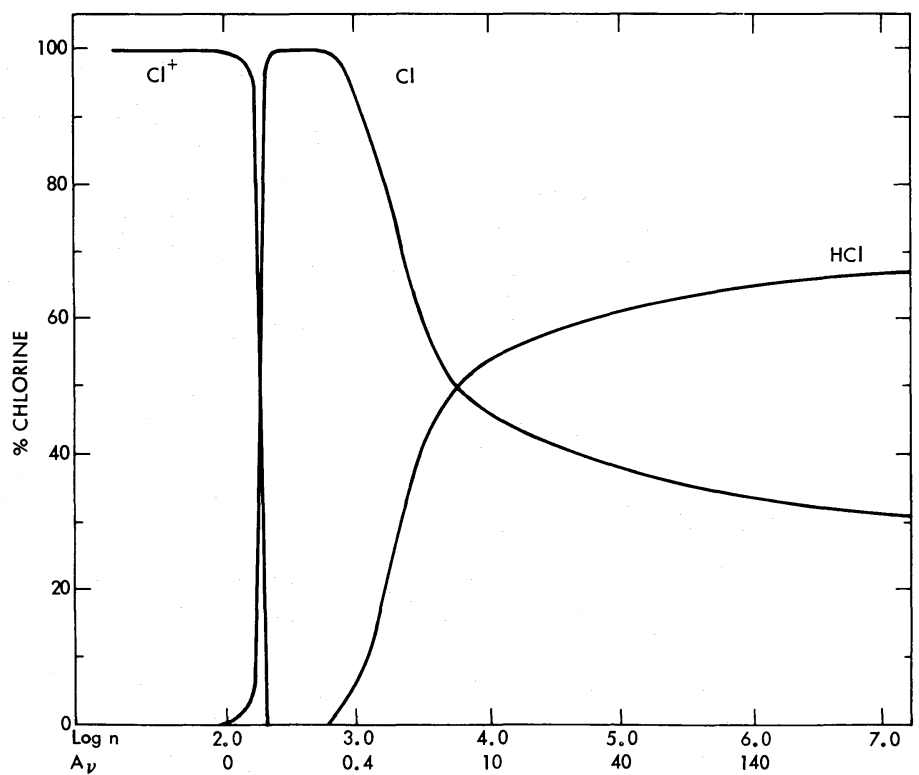

FIG. 2.-Variation of the $\mathrm{Cl} / \mathrm{HCl}$ abundance with density $\left(A_{v}\right)$. The $A_{v}$ scale has been established using the collapsing cloud model of Tarafdar $e$ al . (1985) for a cloud of total mass $1000 M_{\odot}$.

column density or number density and that chlorine may be depleted by a factor of 5 or more. In any case, the estimated chlorine depletion in dense clouds appears to be at most a factor of 10 above that in diffuse clouds, which implies that, compared with other more refractory second-row elements like $\mathrm{Si}$ and $\mathrm{P}$, gas-phase chlorine species may well remain abundant even in the cores of dense molecular clouds.

The research described in this paper was performed by the Jet Propulsion Laboratory, California Institute of Technology, under contract with the National Aeronautics and Space Administration.

\section{REFERENCES}

Anicich, V. G., Huntress, W. T., and Futrell, J. H. 1976, Chem. Phys. Letters, 40, 233.

Black, J. H., and Dalgarno, A. 1977, Ap. J. Suppl., 34, 405.

Blake, G. A., Keene, J., and Phillips, T. G. 1985, Ap. J., 285, 501.

Bush, Y. A., McFarland, M., Albritton, D. L., and Schmeltekopf, A. L. 1973, J. Chem. Phys., 58, 3504.

Dagenais, M., Johns, J. W. C., and McKellar, A. R. W. 1976, Canadian J. Phys., 54, 1438.

Dalgarno, A., de Jong, T., Oppenheimer, M., and Black, J. H. 1974, Ap. J. (Letters), 192, L37.

Graedel, T. E., Langer, W. D., and Frerking, M. A. 1982, Ap. J. Suppl., 48, 321.

Harris, A. W., Gry, G., and Bromage, G. E. 1984, Ap. J., 284, 157.

Hartman, K. N., Lias, S., Ausloos, P., Rosenstock, H. M., Schroyer, S. S., Schmidt, C., Martinsen, and Milne, G. W. A. 1979, NBS Tech. Rept., NBS1R-79-1777.

Johansson, L. E. B., Andersson, C., Ellder, J., Friberg, P., Hjalmarson, B. Irvine, W. M., Olofsson, H., and Rydbeck, G. 1984, Astr. Ap., 130, 227.

Jura, M. 1974, Ap. J. (Letters), 190, L33.

Jura, M., and York, D. G. 1978, Ap. J., 219, 861

Keene, J., Blake, G. A., Phillips, T. G., Huggins, P. J., and Beichman, C. A. 1985, Ap. J., 299, 967

Leung, C. M., Herbst, E., and Huebner, W. F. 1984, Ap. J. Suppl., 56, 231.
Levin, R. D., and Lias, S. G. 1982, NSROS-NBS, No. 71.

Prasad, S. S., and Huntress, W. T. 1980, Ap. J. Suppl., 43, 1.

Rosenstock, H. M., Draxyl, K., Steiner, B. W., and Herron, J. T. 1977, J. Phys. Chem. Ref. Data Suppl., 6, 1.

Smith, D., and Adams, N. G. 1981, M.N.R.A.S., 197, 377.

.1985, private communication.

Smith, P. L., Yoshino, K., Black, J. H., and Parkinson, W. H. 1980, Ap. J., 238, 874 .

Sutton, E. C., Blake, G. A., Masson, C. R., and Phillips, T. G. 1985, Ap. J. Suppl., 58, 341 .

Tarafdar, S. P., Prasad, S. S., and Huntress, W. T., Jr. 1983, Ap. J., 267, 156.

Tarafdar, S. P., Prasad, S. S., Huntress, W. T., Jr., Villere, K. R., and Black, D. C. $1985, A$ p. J., 289, 220

Thorne, L. R., Anicich, V. G., and Huntress, W. T. 1983, Chem. Phys. Letters, 98, 162 .

Thorne, L. R., Anicich, V. G., Prasad, S. S., and Huntress, W. T., Jr. 1984, Ap. $J ., 280,139$.

van Dishoeck, E. F. 1984, Ph.D. thesis, University of Leiden.

van Dishoeck, E. F., van Hemert, M. C., and Dalgarno, A. 1982, J. Chem. Phys., 77, 3693

Watson, W. D., Anicich, V. G., and Huntress, W. T. 1976, Ap. J. (Letters), 205, L165.

Vincent G. Anicich and Wesley T. Huntress, Jr.: Jet Propulsion Laboratory, MS 183-601, 4800 Oak Grove Drive, Pasadena, CA 91109

Geoffrey A. Blake: Downs Laboratory of Physics, 320-47, California Institute of Technology, Pasadena, CA 91125 